University of Nebraska - Lincoln

DigitalCommons@University of Nebraska - Lincoln

$3-2008$

\title{
Can Positive Employees Help Positive Organizational Change? Impact of Psychological Capital and Emotions on Relevant Attitudes and Behaviors
}

\author{
James Avey \\ Central Washington University, aveyj@cwu.edu \\ Tara S. Wernsing \\ University of Nebraska - Lincoln, Tara.Wernsing@ie.edu \\ Fred Luthans \\ University of Nebraska - Lincoln, fluthans1@unl.edu
}

Follow this and additional works at: https://digitalcommons.unl.edu/managementfacpub

Part of the Management Sciences and Quantitative Methods Commons

Avey, James; Wernsing, Tara S.; and Luthans, Fred, "Can Positive Employees Help Positive Organizational Change? Impact of Psychological Capital and Emotions on Relevant Attitudes and Behaviors" (2008). Management Department Faculty Publications. 32.

https://digitalcommons.unl.edu/managementfacpub/32

This Article is brought to you for free and open access by the Management Department at DigitalCommons@University of Nebraska - Lincoln. It has been accepted for inclusion in Management Department Faculty Publications by an authorized administrator of DigitalCommons@University of Nebraska - Lincoln. 


\title{
Can Positive Employees Help Positive Organizational Change? Impact of Psychological Capital and Emotions on Relevant Attitudes and Behaviors
}

\author{
James B. Avey \\ Central Washington University \\ Tara S. Wernsing \\ Fred Luthans \\ University of Nebraska-Lincoln
}

\begin{abstract}
:
Although much attention has been devoted to understanding employee resistance to change, relatively little research examines the impact that positive employees can have on organizational change. To help fill this need, the authors investigate whether a process of employees' positivity will have an impact on relevant attitudes and behaviors. Specifically, this study surveyed 132 employees from a broad cross-section of organizations and jobs and found: (a) Their psychological capital (a core factor consisting of hope, efficacy, optimism, and resilience) was related to their positive emotions that in turn were related to their attitudes (engagement and cynicism) and behaviors (organizational citizenship and deviance) relevant to organizational change; (b) mindfulness (i.e., heightened awareness) interacted with psychological capital in predicting positive emotions; and (c) positive emotions generally mediated the relationship between psychological capital and the attitudes and behaviors. The implications these findings have for positive organizational change conclude the article.
\end{abstract}

Keywords: psychological capital, positive emotions, mindfulness, cognitive mediation theory, positive organizational change

$\mathrm{B}$ oth scholars and practitioners would agree that employee resistance to change is a primary obstacle for effective organizational change processes and programs (Armenakis \& Bedeian, 1999; O'Toole, 1995; Strebel, 1996), 
whether incremental or discontinuous change (Tushman \& O'Reilly, 1996). In particular, resistance manifested through employee dysfunctional attitudes (e.g., disengagement or cynicism) and behaviors (e.g., deviance) can be devastating to effective organizational change (Abrahamson, 2000; Reichers, Wanous, \& Austin, 1997; Stanley, Meyer, \& Topolntsky, 2005). While much attention has been given to such perspectives and how to overcome resistance to change, the role that positive employees may play in positive organizational change has been largely ignored. Although the importance of positive constructs has been recognized from the beginning of organizational behavior research and the study of organization development and change (e.g., the happy worker productive worker thesis; for the history of positivity in the workplace see Quick \& Quick, 2004; Wright \& Cropanzano, 2004), only recently has a positive approach received focused research attention as is found in this special issue of The Journal of Applied Behavioral Science.

Although there are numerous conceptions and definitions, the perspective taken by this study is that organizational change initiates from a mismatch with the environment (Porras \& Silvers, 1994) and is motivated by gaps between the organization's goals and current results. This organization change is both critical for managers in terms of effective implementation and for employees in terms of acceptance and engagement. More than a decade ago, Strebel (1996) argued that vision and leadership drive successful organizational change but that few leaders recognize the importance of the employees' commitment to changing. Employees within the organizational system are responsible for adapting and behaving in ways aligned with change strategies and programs initiated by management, often with fewer resources than before (Mishra, Spreitzer, \& Mishra, 1998). With the change, they must learn to forge new paths and strategies to attain redefined goals. They must have the confidence (efficacy) to adapt to organizational change as well as the resilience to bounce back from setbacks that are bound to occur during the change process. Moreover, it follows that to be successful, employees undergoing change would need to have the motivation and alternate pathways determined (i.e., hope) when obstacles are encountered and make optimistic attributions of when things go wrong and have a positive outlook for the future. Gittell, Cameron, Lim, and Rivas (2006) explain that positive relationships can be one source for developing some of these ways, such as resilience when faced with change, and we add to this research by highlighting the positive processes that may be available to support employees who are facing organizational change.

Based on positive psychology (Seligman \& Csikszentmihalyi, 2000), we propose the newly emerging fields of positive organizational scholarship (Cameron \& Caza, 2004; Cameron, Dutton, \& Quinn, 2003; Roberts, 2006) and positive organizational behavior (Luthans, 2002a, 2002b; Nelson \& Cooper, 2007; Wright, 2003) may offer insights into effective organizational change. In particular, this study investigates whether employees' psychological resources, such as hope, optimism, efficacy, and resilience (i.e., what has been termed their positive psychological capital, PsyCap for short; see Luthans, Avolio, Avey, \& Nor- 
man, 2007; Luthans \& Youssef, 2004; Luthans, Youssef, \& Avolio, 2007), and positive emotions (e.g., see Fredrickson, 1998; Lord, Klimoski, \& Kanfer, 2002; Staw, Sutton, \& Pelled, 1994) are examples of positive individual-level factors that may facilitate organizational change. In other words, positive employees, defined here as those with positive psychological capital and positive emotions, may exhibit attitudes and behaviors that in turn may lead to more effective and positive organizational change.

For this study, positive organizational change is any change that does more good than harm in and for an organization, considering aspects of employees' psychological resources, behavior, and performance that may be affected by the change. An important consideration in positive change is the corresponding effects on employees as well as organizational outcomes. For example, downsizing is a change intended to be positive by increasing organizational efficiency but often fails to be positive because of its disastrous effects on employees (Cascio, 2002). It follows from this perspective that one of the most important aspects of positive organizational change is how the employees respond in terms of their attitudes and behaviors.

To explicate the relationship between positive employees and their attitudes and behaviors that have implications for positive organizational change, we can draw from a stream of research in positive psychology. Specifically, Fredrickson's $(1998,2001,2003 b)$ broaden and build theory examining the role that positive emotions play in generating broader ways of thinking and behaving seems especially relevant to explaining the role that positive employees can play in positive organizational change. Research on positive emotions shows that a ratio of about 3:1 positive to negative emotions leads to flourishing (i.e., high levels of functioning and wellbeing; Keyes, 2002) due to increased "momentary thoughtaction repertoires" (Fredrickson, 2001, p. 219) that come from experiencing positive emotions (Fredrickson \& Losada, 2005). Additional empirical evidence demonstrates that positive emotions can engender better decision making (Chuang, 2007) and are positively related to various measures of success and well-being (Lyubomirsky, King, \& Diener, 2005). In other words, positive emotions may help employees cope with organizational change by broadening the options they perceive, maintaining an open approach to problem solving, and supplying energy for adjusting their behaviors to new work conditions (Baumeister, Gailliot, DeWall, \& Oaten, 2006).

For this study, the proposed process and empirical relationship between positive employees and positive organizational change is as follows: Employees' positive PsyCap, through positive emotions, relates to their relevant attitudes and behaviors that can facilitate (or inhibit) positive organizational change. More specifically, cynical attitudes and deviant behaviors may inhibit positive change, but their attitudes of engagement and organizational citizenship behaviors may enhance positive organizational change. We now turn to the background leading up to the specific study hypotheses for this proposed process shown in Figure 1. 


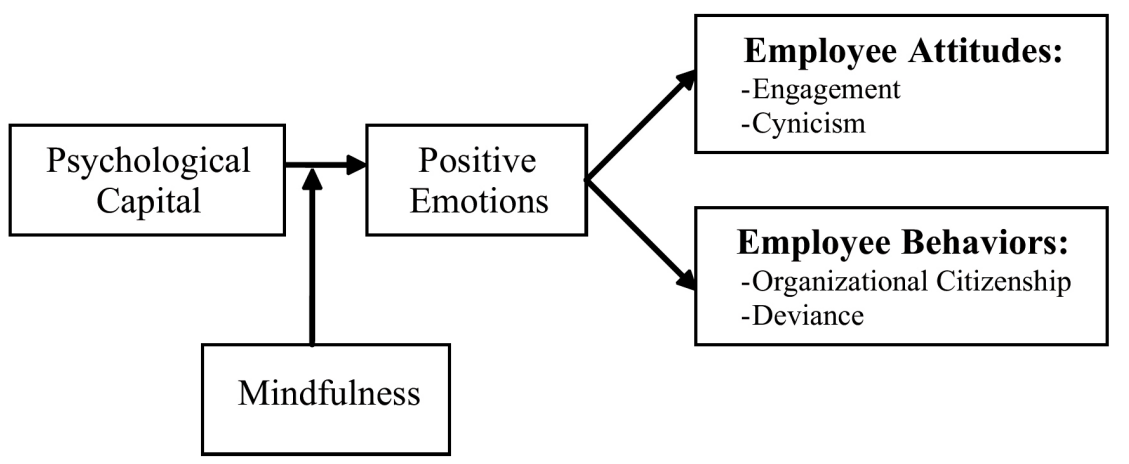

Figure 1: Model for Impact of Psychological Capital (PsyCap), Mindfulness, and Positive Emotions on Attitudes and Behaviors Relevant to Positive Organizational Change

\section{The Role of Emotions, Attitudes, and Behaviors in Organizational Change}

In this study we investigate the impact that positive employees, represented by their levels of psychological capital (covered next) and positive emotions, and their relevant attitudes and behaviors may have on positive organizational change. Based on Fredrickson's (1998, 2001, 2003b) work, we propose positive emotions will result in higher levels of engagement attitudes and organizational citizenship behaviors that would facilitate positive change. By the same token, those employees who are low in PsyCap will experience lower levels of positive emotions and in turn are more likely to experience cynical attitudes and deviant behaviors that would be indicative of resistance to change and detract from positive organizational change.

Relevant prior research by Staw and colleagues (Staw \& Barsade, 1993; Staw et al., 1994; Wright \& Staw, 1999) has found that employees who report more frequent levels of positive emotions tended to be more socially integrated in the organization, thus likely leading to higher engagement and citizenship than those who reported fewer positive emotions. In terms of work attitudes, Fredrickson's (2001) broaden and build theory of positive emotions predicts that positive emotions "broaden people's momentary thought-action repertoires, widening the array of the thoughts and actions that come to mind" (p. 220). She further notes "the personal resources accrued during states of positive emotions are conceptualized as durable" (p. 220). It would follow that these psychological resources generated by employees experiencing positive emotions may lead to employee attitudes such as emotional engagement. This employee engagement would not only affect individual employees but may also impact other team members' motivation and emotions, which in turn can be a positive influence on organizational change (Bakker, van Emmerik, \& Euwema, 2006). 
Fredrickson and colleagues' (Fredrickson, 1998, 2001; Fredrickson, Mancuso, Branigan, \& Tugade, 2000) work also provides insight into the role positive emotions may play in influencing negative attitudes such as cynicism toward organizational change. For example, she notes the undoing hypothesis of positive emotions: Positive emotions "undo" the dysfunctional effects of negative emotions (Fredrickson \& Levenson, 1998). Because organizational cynicism is an individual attitude (Dean, Brandes, \& Dharwadkar, 1998) associated with negative emotions (Andersson \& Bateman, 1997), it follows from Fredrickson's "undoing hypothesis" that employees high in positive emotions will be expected to have fewer cynical attitudes regarding organizational change. Because cynicism is a result of negative experiences and emotions (Pugh, Skarlicki, \& Passell, 2003), Fredrickson's research would suggest that such cynical attitudes toward organizational change would be undone or decreased by positive emotions.

Furthermore, because Fredrickson's broaden and build theory argues that positive emotions broaden both thought and action repertoires, we also propose that positive emotions will affect employees' behaviors with regard to organizational change. Specifically, Fredrickson (2003a) argues that while the absence of positive emotions limits thought-action repertoires to instinctual human functioning (e.g., fight or flight) leading to more short-term thinking and undesirable organizational outcomes, the presence of positive emotions broadens thought-action repertoires to consider a wider array of positive behavioral manifestations toward organizational change. In other words, those experiencing positive emotions may engage in fewer deviant behaviors and more positive citizenship behaviors in regard to organizational change. Given the aforementioned proposed relationships of positive emotions with both employee attitudinal and behavioral outcomes, the following study hypotheses are derived:

Hypothesis 1: Positive emotions will be positively related to employee attitudes of engagement and negatively to organizational cynicism.

Hypothesis 2: Positive emotions will be positively related to employee behaviors of organizational citizenship and negatively to workplace deviance.

\section{Psychological Capital}

Besides the roles of emotions, attitudes, and behaviors, central to our proposed model of the relationship of positive employees in positive organizational change is psychological capital. This PsyCap is based on the emerging field of positive organizational behavior (for a recent review article, see Luthans \& Youssef, 2007). Like psychology, positive organizational behavior makes no claim to discovering the importance of positivity in the workplace but rather is simply calling for a focus on relatively unique positive, state-like constructs that have performance impact (see Luthans, 2002a, 2002b). To differentiate from the positively oriented popular personal development literature (e.g., the power of positive thinking or the seven habits of highly successful people) or the relatively fixed, trait-like positively oriented organizational behavior litera- 
ture (e.g., Big Five personality dimensions or core self-evaluations), the following definition of positive organizational behavior has been offered: "the study and application of positively oriented human resource strengths and psychological capacities that can be measured, developed, and effectively managed for performance improvement" (Luthans, 2002b, p. 59; also see Luthans \& Youssef, 2007; Nelson \& Cooper, 2007; Wright, 2003).

Although a number of positive constructs have been researched (e.g., see Cameron et al., 2003; Nelson \& Cooper, 2007), so far the four that have been identified to best meet the criteria of the definition of positive organization behavior are hope, efficacy, optimism, and resilience (Luthans, 2002a; Luthans, Youssef, et al., 2007). When combined, these four have been conceptually (Luthans \& Youssef, 2004; Luthans, Youssef, et al., 2007) and empirically (Luthans, Avolio, et al., 2007) demonstrated to represent a second-order, core factor called psychological capital. After a brief overview of the four components and their relevancy to positive organizational change, the precise meaning of PsyCap is provided as it is a major predictor variable in the proposed process shown in Figure 1.

Conceptually, Snyder, Irving, and Anderson (1991) define hope as a "positive motivational state that is based on an interactively derived sense of successful (1) agency (goal-directed energy) and (2) pathways (planning to meet goals)" (p. 287). People who are high in hope possess the uncanny ability to generate multiple pathways to accomplishing their goals. This psychological resource continuously provides hope that the goal will be accomplished. Furthermore, those with high hope frame tasks in such a way that keeps them highly motivated to attain success in the task at hand. Snyder (2002) notes that agency thinking in hope "takes on special significance when people encounter impediments. During such instances of blockage, agency helps the person to apply the requisite motivation to the best alternative pathway" (p. 258). Therefore, both agency and pathways thinking are necessary and complementary components of hope. Sustaining hope during times of crises and change seems imperative for the well-being of employees and a necessary ingredient of positive organizational change. In particular, the capacity for generating new pathways seems essential to navigating discontinuous and unpredictable change processes (Weick \& Quinn, 1999).

A second capacity of PsyCap is efficacy. Drawn from the theory and research of Bandura (1997), applied to the workplace, efficacy can be defined as "the employee's conviction or confidence about his or her abilities to mobilize the motivation, cognitive resources, or courses of action needed to successfully execute a specific task within a given context" (Stajkovic \& Luthans, 1998b, p. 66). In relationship to hope, efficacy can be interpreted as the conviction and belief in one's ability to (a) generate multiple pathways, (b) take actions toward the goal, and (c) ultimately be successful in goal attainment. Efficacy has shown very strong relationships with performance (e.g., meta-analysis by Stajkovic \& Luthans, 1998a) and is generated from four generally recognized sources that are all relevant to positive organizational change.

First, Bandura (1997) has conceptually and empirically demonstrated that task mastery, or successfully accomplishing a task, is a primary source of efficacy. When employees successfully accomplish a task or cope with change, they are more likely to believe they can do it again. Other major sources of efficacy in- 
clude watching someone considered similar to oneself successfully accomplish a task or cope with change (vicarious learning or modeling), being assured by a respected role model (e.g., a coach or mentor) that one will be successful in a new task or in the change process (social persuasion), and being emotionally and physically motivated to complete the task or cope with the change (arousal). Employees that are highly efficacious are characterized by tenacious pursuit and persistent efforts toward accomplishment and are driven by beliefs in their own successes. In other words, efficacy seems vitally important to effective organizational change efforts because employees are often required to take on new responsibilities and skills. Simply focusing time on early task mastery experiences, role modeling, and greater social support can move employees toward higher levels of efficacy in the changing workplace.

A third criteria-meeting positive resource of PsyCap is optimism. Carver and Scheier (2002) note quite simply that "optimists are people who expect good things to happen to them; pessimists are people who expect bad things to happen to them" (p. 231). This statement represents the expectancy framework used to understand the influential role of optimism in one's success in undergoing organizational change. Under this perspective, those high in optimism characteristically expect success when faced with change. It is important to note that optimistic expectations in this case are an individual-level attribution. It is not likely that optimists expect organizational change efforts to be successful because of their optimism. Rather, optimists tend to maintain positive expectations about what will happen to them personally throughout the change process.

This optimism is in contrast with efficacious people who believe positive outcomes will occur given their belief that their personal ability will lead to success through making a change. Optimistic people expect positive outcomes for themselves regardless of personal ability. In addition to this positive future expectation, Seligman (1998) proposes a complementary optimistic framework based in attributions or what he calls explanatory style. Optimists tend to make internal, stable, and global attributions for successes and external, unstable, and specific attributions for failures. Thus, should a negative outcome occur during the process of change, optimists would tend to remain motivated toward success because they conclude the failure was not due to something inherent in them (external) but was instead something unique in that situation (specific) and a second attempt will likely not result in failure again (unstable). Therefore, the optimistic employee can continue to move forward with positive expectations regardless of past problems or setbacks.

The fourth positive capacity making up PsyCap is resilience. Given the turbulent socioeconomic and "downsizing" types of adverse change facing most of today's organizations and employees, Luthans (2002a) defines resilience as a "positive psychological capacity to rebound, to 'bounce back' from adversity, uncertainty, conflict, failure, or even positive change, progress and increased responsibility" (p. 702). At the core of this capacity is the bouncing back (and beyond) from setbacks and positively coping and adapting to significant changes. Masten and Reed (2002) assert resilience is "a class of phenomena characterized by patterns of positive adaptation in the context of significant adversity or risk" (p. 74). Thus, resilient employees are those who have the ability to positively 
adapt and thrive in very challenging circumstances such as involved in most organizational change.

The aforementioned indicates that employees high in the four components making up PsyCap could have a variety of positive psychological resources to draw from to cope with the challenges of organizational change. This combined effect of PsyCap has been defined as

an individual's positive psychological state of development that is characterized by: (1) having confidence (self efficacy) to take on and put in the necessary effort to succeed at challenging tasks; (2) making a positive expectation (optimism) about succeeding now and in the future; (3) persevering toward goals and, when necessary, redirecting paths to goals (hope) in order to succeed; and (4) when beset by problems and adversity, sustaining and bouncing back and even beyond (resilience) to attain success. (Luthans, Youssef, et al., 2007, p. 3)

As a higher-order core capacity, PsyCap has an underlying common thread and shared characteristics running through each of the psychological resource capacities (i.e., efficacy, optimism, hope, and resiliency) of positive agentic (intentional) striving toward flourishing and success, no matter what changes and challenges arise. This PsyCap core construct has been found to be validly measurable and related to several key workplace outcomes, including employee performance, job satisfaction, and absenteeism (Avey, Patera, \& West, 2006; Luthans, Avolio, et al., 2007). Research has also shown that the overall core construct of PsyCap better relates to these outcomes than the individual constructs that make it up (Luthans, Avolio, et al., 2007; Luthans, Avolio, Walumbwa, \& $\mathrm{Li}, 2005)$. Finally, there is beginning evidence that PsyCap is open to development in short training interventions (see Luthans, Avey, Avolio, Norman, \& Combs, 2006; Luthans, Avey, \& Patera, in press).

\section{The Mediating Role of Positive Emotions}

As shown in Figure 1, PsyCap is related to positive emotions, and positive emotions in turn are related to employee attitudes and behaviors relevant to positive organizational change. Thus, we are proposing that positive emotions mediate the relationship between PsyCap and attitudes and behaviors. Although the powerful effects of positive emotions have been empirically demonstrated in the workplace (for a review, see Brief \& Weiss, 2002; Lord et al., 2002; Payne \& Cooper, 2001), there is still debate on whether cognition precedes emotion or vice versa (e.g., see Izard, 1993; Lazarus, 2006). In any case, there seems to be a closely linked and reciprocal relationship between cognition and emotion. There is evidence that thoughts cause emotional responses (Frijda, 1986; Lazarus \& Folkman, 1984; Ortony, Clore, \& Collins, 1988), cognition creates labels used to identify physiological feelings as discrete emotions (Schachter \& Singer, 1962), and emotions in turn are a source for information processing and decision making (Albarracin \& Kumkale, 2003; Schwarz \& Clore, 1983). We propose that Lazarus's (1991, 1993, 2006) cognitive mediation theory that views appraisals and evaluations as the basis for emotional response elicitation is the most relevant framework for the workplace, as demonstrated by affective events theory developed by Weiss and Cropanzano (1996). 
Affective events theory explains that an event elicits an initial evaluation "for relevance to well-being in simple positive or negative terms. This initial evaluation also contains an important evaluation which influences the intensity of the emotional reaction" (Weiss \& Cropanzano, 1996, p. 31) and leads to a secondary appraisal associated with discrete emotions. These initial and secondary appraisals can occur automatically, below the threshold of conscious awareness (Bargh, 1994). Therefore, multiple appraisals occur from events experienced at work that generate emotions.

For example, research shows that the same event can occur to two different people and cause stressful emotions in one of them but not in the other (Lazarus \& Folkman, 1984). Thus, employees may automatically interpret organizational change events in ways that cause them to experience dysfunctional attitudes such as cynicism and exhibit deviant behaviors, perhaps even without conscious awareness of the connection between their thoughts and emotions. On the other hand, those employees who interpret events in a positive way, namely, with hope, optimism, efficacy, and resilience (i.e., PsyCap), may be more likely to experience positive emotions at work even during potentially stressful events associated with organizational change. Therefore, as shown in Figure 1, PsyCap is proposed as a source of positive emotions.

We suggest that overall PsyCap will contribute to individual positive emotions. For example, first, if employees are optimistic and efficacious, they generally possess positive expectations for goal achievement and successfully coping with change and thus experience positive feelings of confidence. Positive emotions are in turn likely to broaden or multiply the pathways that are generated in goal pursuit (Fredrickson, 2001). If a setback or challenge occurs during a process of change, they are likely to attribute the setback to external, one-time circumstances and immediately consider alternative pathways to goal success, demonstrating hope and resilience. Tugade and Fredrickson (2004) also support the position that cognitive states and abilities such as resilience precede positive emotions and found that "high-resilient individuals tend to experience positive emotions even amidst stress" (p. 331). As organizational transitions are associated with higher levels of stress (Ashford, 1988), PsyCap may help maintain a more positive climate during such periods of change.

Martin, Jones, and Callan (2005) have recently extended Lazarus and Folkman's (1984) research on stress and coping to show that employee perceptions of organizational climate affect their appraisals and emotions, which affect their organizational commitment, job satisfaction, and absenteeism. In addition, related research in positive psychology also suggests the mediating role of positive emotions. For example, Tugade, Fredrickson, and Barrett (2004) found that those individuals higher in resilience used positive emotions to cope during and after stressful events. Similar results were found by Fredrickson, Tugade, Waugh, and Larkin (2003) when studying the role of resilience in responding to the $9 / 11$ attacks in New York.

In sum, we posit a mediating role of positive emotions in the relationship between PsyCap and employee attitudes and behaviors relevant to organizational change. In particular, given (a) the explanatory framework of the cognitive mediation theory that proposes cognitions precede emotions; (b) previous 
research such as by Tugade, Fredrickson, and colleagues (2004) that support the mediating role of positive emotions; (c) the hypothesized relationship between PsyCap and positive emotions; and (d) the hypothesized relationship between positive emotions and employee attitudes and behaviors, we expect that positive emotions will mediate the relationship between PsyCap and the attitudes and behaviors relevant to organizational change. Specifically, we derive the following study hypotheses:

Hypothesis 3: PsyCap will be positively related to positive emotions.

Hypothesis 4: Positive emotions will mediate the relationship between PsyCap and the attitudes of engagement and cynicism and the behaviors of organizational citizenship and deviance.

\section{The Interactive Role of Mindfulness}

Figure 1 shows that psychological capital predicts positive emotions, and now we examine whether heightened awareness can affect this relationship. Specifically, can greater mindfulness result in higher levels of positive psychological capital and emotions? Perhaps the more mindful awareness employees have of their PsyCap and positive emotions, or lack thereof, the more it can facilitate positive attitudes and behaviors relevant to organizational changes. To investigate this question, we tested whether mindfulness, through an interaction with PsyCap, may provide further insight into this process.

Mindfulness is defined as "enhanced attention to and awareness of current experiences or present reality" (Brown \& Ryan, 2003, p. 823). To date, this concept has been tied to positive psychological and physiological well-being (Baer, 2003; Carlson, Speca, Patel, \& Goodey, 2004; Kabat-Zinn, 2003; Wallace \& Shapiro, 2006) through providing greater nonjudgmental awareness of one's internal and external environment (Germer, Siegel, \& Fulton, 2005; Langer, 1997; Sternberg, 2000; Teasdale, Segal, \& Williams, 1995).

Mindfulness has been applied to organizational settings requiring high reliability (Weick \& Sutcliffe, 2001). Weick, Sutcliffe, and Obstfeld (1999) define mindfulness as enhanced awareness of discriminatory detail of organizational processes. Specifically, "mindful organizing" in high-reliability contexts consists of greater attention to detecting failure, reluctance to simplify interpretations, more time observing operations, and more time developing resilience to unexpected events (Weick \& Sutcliffe, 2006). Based on this latter point, mindfulness as a form of heightened attention and awareness seems likely to be related to resilience and other psychological capital components as well.

Given that mindfulness can help in "disengaging individuals from unhealthy thoughts, habits and unhealthy behavior patterns" (Brown \& Ryan, 2003, p. 823), it follows that becoming more mindful of one's thoughts and emotional response patterns can be a source for altering them and therefore be important to supporting positive organizational change. For example, if an employee becomes more aware of a pessimistic thinking pattern regarding changes at work, potentially through practicing greater mindfulness, this employee can use self- 
monitoring to identify unproductive thinking habits and choose more positive interpretations, thus reducing negative emotions over time. This reduction happens as mindfulness moves the individual from being embedded in their thinking to being able to step outside and observe it. As Bandura (1991) points out: "People cannot influence their own motivation and actions very well if they do not pay adequate attention to their own performances" (p. 250). Thus, mindfulness seems to be an important factor that interacts with PsyCap to influence positive emotions that support positive organizational change, which leads us to the final study hypothesis:

Hypothesis 5: Mindfulness will moderate the positive relationship between PsyCap and positive emotions such that when PsyCap is low, mindfulness will have a stronger relationship with positive emotions.

\section{Method}

\section{Sample}

The heterogeneous sample for this study was comprised of 132 working adults from a wide cross-section of U.S. organizations who volunteered to participate in a large Midwestern university-sponsored research project on motivation and leadership. Participants were targeted through contacts of management faculty and students at the university. Those who agreed to participate were provided a link to an online secure server, where they read and approved the informed consent form and registered their e-mail address. At this point they were assigned a randomly generated seven-digit code for tracking, and 132 fully participated and completed all of the survey measures described in the following section.

Participant ages ranged from 18 to 65 with a mean age of 30.4 years. They had a mean of 10.8 years of experience and 6 years at their existing organization. The majority of the sample was white (90.2\%), with $5.3 \%$ Asian, $1 \%$ black, $1 \%$ Native American, and the rest $(<2 \%)$ not reporting ethnicity. There were 68 men and 64 women, and 32\% reported working virtually from their manager $50 \%$ or more of the time. Nonmanagerial employees comprised about two thirds of the sample. Among the $35 \%$ of the sample in some supervisory role, $8.5 \%$ were in a first-level supervisory role, $13.2 \%$ were in a division or department leadership role, $8.5 \%$ were executives, and $4.7 \%$ were business owners. Finally, 3.8\% reported completion of high school only, whereas 52.3\% reported completion of high school and some college or vocational training. Another $34.8 \%$ of participants reported a bachelor's degree, with $7.6 \%$ reporting a master's degree and $1.5 \%$ reporting a $\mathrm{PhD}$ or equivalent.

\section{Study Procedures}

The independent and dependent variable survey measures (covered next) were separated by time to reduce common method bias as recommended by Podsakoff, MacKenzie, Lee, and Podsakoff (2003) who note this temporal separation procedure "makes it impossible for the mindset of the source or rater 
Table 1. Descriptive Statistics, Correlations, and Scale Reliabilities

\begin{tabular}{lrrrrrrrrr}
\hline & $\mathrm{M}$ & $\mathrm{SD}$ & 1 & 2 & 3 & 4 & 5 & 6 & 7 \\
\hline 1. Psychological capital (PsyCap) & 4.56 & 0.63 & .95 & & & & & & \\
2. Mindfulness & 4.07 & 0.76 & .27 & .91 & & & & & \\
3. Positive emotions & 4.51 & 0.66 & .70 & .43 & .95 & & & & \\
4. Engagement & 4.57 & 0.99 & .50 & .26 & .59 & .80 & & & \\
5. Cynicism & 2.95 & 1.00 & -.42 & -.24 & -.39 & -.29 & .95 & & \\
$\begin{array}{l}\text { 6. Deviance } \\
\text { 7. Organizational } \\
\quad \text { citizenship behaviors }\end{array}$ & 1.83 & 0.65 & $-.52-$ & .37 & -.55 & -.48 & .34 & .92 & \\
& 4.04 & 1.00 & .44 & .27 & .42 & .52 & -.30 & -.33 & .90 \\
& & & & & & & & & \\
\hline
\end{tabular}

All relationships significant at $p<.01$. Reliabilities in bold.

to bias the observed relationship between the predictor and criterion variable, thus eliminating the effects of consistency motifs, implicit theories, social desirability tendencies" (p. 887) and other individual attributes that may influence/ bias the responses. First, the participants completed the PsyCap, mindfulness, and positive emotions instruments. After a week of separation the participants logged on and completed the dependent variable instruments for cynicism, employee engagement, organizational citizenship, and deviance.

\section{Measures}

Psychological capital was measured by the 24-item PsyCap questionnaire or PCQ (Luthans, Avolio, et al., 2007; Luthans, Youssef, et al., 2007). This instrument includes 6 items for each of the four components of hope, efficacy, resilience, and optimism measured on a 6-point Likert-type scale. Sample items are as follows: efficacy - "I feel confident helping to set targets/goals in my work area;" hope - "If I should find myself in a jam at work, I could think of many ways to get out of it;" resilience- "I usually take stressful things at work in stride;" and optimism - "When things are uncertain for me at work, I usually expect the best." Reliability coefficients for all the components were greater than .70, as was the overall PsyCap instrument, which was .95 (see Table 1 for the reliabilities of all study measures). A confirmatory factor analysis (CFA) was also conducted on the PsyCap instrument using maximum likelihood techniques. Previous research has shown strong factor-analytic fit for the PsyCap questionnaire across multiple samples (e.g., Avey et al., 2006; Luthans, Avolio, et al., 2007). Similar to these findings, in our study the PCQ yielded adequate fit in terms of indices (Comparative Fit Index [CFI] $=.93$, root mean square error of approximation [RMSEA] $=.07$ ) with all items loading greater than .70 and no cross-loading items.

Mindfulness was measured using the instrument developed by Brown and Ryan (2003), where ratings for 15 items were set on a 6-point scale ranging from strongly disagree to strongly agree. A sample item from this scale is: "I find myself doing things without paying attention." The reliability coefficient for the mindfulness instrument was also acceptable (.91). 
Finally, consistent with research by Tugade and Frederickson (2004), we used Watson, Clark and Tellegen's (1988) Positive and Negative Affect Schedule (PANAS) scale to measure positive emotions. For these analyses, given the explicit focus on positive emotions (PA), we only used the positive emotions listed in the scale, which included interested, excited, strong, enthusiastic, proud, alert, inspired, determined, attentive, and active. Participants rated the frequency they experienced each particular emotion over the last week. This represents a sample of the individual's emotions that is relatively recent, not fixed (e.g., the last year), and not so immediate that a one-time event or day would extremely skew the data (e.g., the last day). The reliability coefficient for positive emotions as measured by the PA scale was acceptable at .95.

The dependent variables measured at Time 2 in this study included both attitudinal (emotional engagement and cynicism) and behavioral (individual organizational citizenship and workplace deviance) scales. Emotional engagement was measured with the scale developed by May and colleagues (May, Gilson, \& Harter, 2004). This scale demonstrated adequate reliability (.80), and a sample item is: "I really put my heart into my job." Cynicism was measured by a 12-item instrument developed by Wanous, Reichers, and Austin (2000). This scale demonstrated adequate reliability (.95), and a sample item from this scale is: "Most of the programs that are supposed to solve problems around here won't do much good."

Individual organizational citizenship behaviors (OCBI) were measured by Lee and Allen's (2002) eight-item OCBI scale, which demonstrated adequate reliability in this study (.90). A sample item is: "I go out of my way to make new employees feel welcome in the work group." Finally, deviance behaviors were measured by Fox and Spector's (1999) counterproductive work behaviors scale. This scale asks respondents to rate the extent to which the individual has engaged in deviant behaviors $(\mathrm{a}=.92)$. We used the minor organizational and the minor personal dimensions of this scale. A sample item from the minor personal scale is "withheld work related information from a co-worker," and a sample item from the minor organizational scale is "purposely wasted company materials/supplies."

\section{Results}

Means, standard deviations, and item correlations for study variables are shown in Table 1. Hypothesis 1 was that employees' positive emotions would be positively related to their emotional engagement and negatively related to their cynicism. For these analyses we used hierarchical regression where the covariates of age, gender, tenure, job level, and education were entered into Step 1 and positive emotions were entered into Step 2. The purpose was to see the independent effects of positive emotions on both attitudes. As seen in Table 2 , when entering positive emotions into the regression model, it predicted significant variance beyond the covariates. In each case, the model in Step 2 shows positive emotions related positively with engagement and negativity with cynicism. Therefore, there was full support for Hypothesis 1. 
Table 2. Effect of Positive Emotions on Attitudes and Behaviors Relevant to Positive Organizational Change

\begin{tabular}{|c|c|c|c|c|c|c|c|c|}
\hline & \multicolumn{2}{|c|}{ Engagement } & \multicolumn{2}{|c|}{ Cynicism } & \multicolumn{2}{|c|}{ Citizenship } & \multicolumn{2}{|c|}{ Deviance } \\
\hline & $\begin{array}{c}\text { Step } 1 \\
\beta\end{array}$ & $\begin{array}{c}\text { Step } 2 \\
\beta\end{array}$ & $\begin{array}{c}\text { Step } 1 \\
\beta\end{array}$ & $\begin{array}{c}\text { Step } 2 \\
\beta\end{array}$ & $\begin{array}{c}\text { Step } 1 \\
\beta\end{array}$ & $\begin{array}{c}\text { Step 2 } \\
\beta\end{array}$ & $\begin{array}{c}\text { Step } 1 \\
\beta\end{array}$ & $\begin{array}{c}\text { Step } 2 \\
\beta\end{array}$ \\
\hline Age & -.045 & .001 & $-.419^{*}$ & $-.449^{*}$ & -.221 & -.186 & -.059 & -.104 \\
\hline Gender & .089 & .045 & -.096 & -.067 & $.254^{* *}$ & $.221^{*}$ & $-.232^{*}$ & $-.189^{*}$ \\
\hline Tenure & .097 & .033 & $.364^{*}$ & $.405^{*}$ & 292 & .244 & -.054 & .010 \\
\hline Job level & .193 & .107 & .035 & .064 & -.020 & -.054 & -.025 & .018 \\
\hline Education & $.274^{* *}$ & .150 & $-.277^{* *}$ & $-.198^{*}$ & $.242 *$ & .150 & $-.206^{*}$ & -.086 \\
\hline Positive emotions & & $.531^{* *}$ & & $-.342^{* *}$ & & $.394^{* *}$ & & $-.519^{* *}$ \\
\hline$\Delta R^{2}$ & & $.256^{* *}$ & & $.106^{* *}$ & & $.141^{* *}$ & & $.245^{* *}$ \\
\hline
\end{tabular}

${ }^{*} p<.05 ;{ }^{* *} p<.01$.

Hypothesis 2 predicted a positive relationship between positive emotions and organizational citizenship behaviors and a negative relationship with workplace deviance behaviors. Similar to the test of Hypothesis 1, hierarchical regression was used with the covariates of age, gender, tenure, job level, and education in Step 1, followed by positive emotions in Step 2. As hypothesized, positive emotions accounted for significant incremental variance in each model and were positively related to citizenship behaviors and negatively related to workplace deviance behaviors as shown in Table 2. Thus, full support was found for Hypothesis 2.

Hypothesis 3 predicted a positive relationship between PsyCap and positive emotions. As evident in Table 4, PsyCap predicted positive emotions above and beyond the control variables used in the study. Thus, we found full support for Hypothesis 3.

Hypothesis 4 indicated positive emotions acted as a mediator between PsyCap and the employee attitudes and behaviors. Baron and Kenny (1986) posit that mediation is supported if each of the following is demonstrated: (a) The first regression equation shows that the independent variable relates to the dependent variable, (b) the second equation shows that the independent variable relates to the mediating variable, and (c) the third regression shows that the mediating variable relates to the dependent variable and the relationship of the independent variable with the dependent variable is significantly lower in magnitude in the third equation than in the second. Support for full mediation can be argued when the independent variable does not relate to the dependent variable when the mediating variable is added to the equation.

Support for the second condition, that the independent variable of PsyCap is related to positive emotions, was found in testing Hypothesis 3 (see Table 4). Therefore, we performed regression analyses to determine the extent to which the independent variable PsyCap was related to the attitudes and behaviors and in Step 2 of the regression model, the extent to which positive emotions negated or minimized that relationship. 
Table 3. Mediating Effect of Positive Emotions on Attitudes and Behaviors Relevant to Positive Organizational Change

\begin{tabular}{|c|c|c|c|c|c|c|c|c|c|c|c|c|}
\hline & \multicolumn{3}{|c|}{ Engagement } & \multicolumn{3}{|c|}{ Cynicism } & \multicolumn{3}{|c|}{ Citizenship } & \multicolumn{3}{|c|}{ Deviance } \\
\hline & Step 1 & Step 2 & Step 3 & Step 1 & 1 Step 2 & 2 Step 3 & Step 1 & Step $2 \mathrm{~s}$ & Step 3 & Step $1 \subseteq$ & Step 2 & Step 3 \\
\hline & $\beta$ & $\beta$ & $\beta$ & $\beta$ & $\beta$ & $\beta$ & $\beta$ & $\beta$ & $\beta$ & $\beta$ & $\beta$ & $\beta$ \\
\hline Education & -.045 & -.021 & .001 & $-.419^{*}$ & $-.442 *$ & $-.448^{*}$ & -.221 & -.200 & -.187 & -.059 & -.084 & -.103 \\
\hline Gender & .089 & .017 & .032 & -.096 & -.028 & -.033 & $.254^{*}$ & $.190^{*}$ & * . $.199 *$ & $-.232^{*}$ & -.155 & $-.167^{*}$ \\
\hline Age & .097 & .026 & .023 & .364 & $.430^{*}$ & * .431* & .292 & .229 & .227 & -.054 & .023 & .026 \\
\hline Job level & .153 & .111 & .103 & .035 & .074 & .077 & -.020 & -.057 & -.062 & -.025 & .019 & .026 \\
\hline Tenure & $.274^{*}$ & $.189^{*}$ & .145 & $-.277^{*}$ & $-.198 *$ & ${ }^{*}-.185^{*}$ & $.242^{*}$ & .168 & .142 & $-.206^{*}$ & -.116 & -.078 \\
\hline \multicolumn{2}{|c|}{$\begin{array}{l}\text { Psychological } \\
\text { capital (PsyCap) }\end{array}$} & $.429^{*}$ & .118 & & $-.401^{*}$ & ** $-.306^{*}$ & & $.379^{* *}$ & ** .199 & & $-.461^{* *}$ & *-.192 \\
\hline \multicolumn{2}{|c|}{ Positive emotions } & $.452 *$ & & & -.138 & & & $.262^{*}$ & & & $-.391^{* *}$ & \\
\hline
\end{tabular}

${ }^{*} p<.05 ;{ }^{* *} p<.01$.

As shown in Table 3, the results of the analyses for Hypothesis 4 were mixed. When entered into Step 3 of the regression model, positive emotions were related to engagement and negated the previously significant relationship between PsyCap and engagement. Therefore, positive emotions were found to fully mediate the relationship between PsyCap and engagement. In contrast, positive emotions did not negate the significant negative relationship between PsyCap and cynicism, and neither were positive emotions significantly negatively related to cynicism with PsyCap in the regression model. Thus, PsyCap was shown to have an independent effect on cynicism apart from positive emotions. Given that cynicism is an attitude that is recognized to be made up of both cognitive and affective components (Dean et al., 1998), the empirical evidence suggests that the cognitive component of this attitude primarily drives the negative relationship between PsyCap and cynicism.

For the final two outcomes in the study, citizenship and deviance behaviors, positive emotions were found to fully mediate their relationship with PsyCap. In each case, Step 2 shows PsyCap to be a significant predictor, then in Step 3 positive emotions were found to negate that relationship and emerge as the stronger and significant predictor of both citizenship and deviance behaviors.

Hypothesis 5 was that mindfulness would moderate the relationship between PsyCap and positive emotions. Thus, we calculated an interaction term (using centered terms) and included it in the hierarchical analyses. In addition, we included education, gender, age, job level, and tenure as covariates in our analyses. As evident by the results shown in Table 4, we found full support for Hypothesis 5; however, the interaction effect was different than we expected.

The graph in Figure 2 plots high and low levels of mindfulness and PsyCap according to procedures in Aiken and West (1991). Specifically, the interaction effects were examined using standard deviations above and below the mean and by selecting values for high and low levels of each variable (i.e., 2 for low and 6 for high); the latter results are presented in Figure 2. As depicted by this graph, mindfulness significantly $(\beta=-.15 ; p<.05)$ interacts with PsyCap to pre- 
Table 4. Interactive Effect of Mindfulness on Psychological Capital (PsyCap) and Positive Emotions

\begin{tabular}{lccc}
\hline & \multicolumn{3}{c}{ Positive Emotions } \\
\cline { 2 - 4 } & Step 1 & Step 2 & Step 3 \\
& $\beta$ & $\beta$ & $\beta$ \\
\hline Age & -.097 & -.065 & -.056 \\
Gender & -.092 & -.047 & -.047 \\
Tenure & .123 & -.020 & -.016 \\
Job level & .099 & .058 & .059 \\
Education & $.227^{*}$ & .055 & .058 \\
PsyCap & & $.640^{* *}$ & $.690^{* *}$ \\
Mindfulness & & $.250^{* *}$ & $.226^{*}$ \\
PsyCap $\times$ Mindfulness & & & $-.152^{*}$ \\
$\Delta R^{2}$ & & $.473^{* *}$ & $.020^{*}$ \\
\hline
\end{tabular}

${ }^{*} p<.05 ;{ }^{* *} p<.01$.

dict positive emotions such that the relationship between mindfulness and positive emotions is stronger when PsyCap is lower. However, when PsyCap is high, mindfulness does not have a significant effect on positive emotions. Therefore, the compensatory effect of mindfulness on positive emotions occurs only when PsyCap is low. A test of the simple slopes confirms that the relationship between PsyCap and positive emotions is significantly different than zero at the levels of mindfulness examined ( $t$ tests significant at $p<.001$ ).

\section{Post Hoc Analyses}

Subsequent to all hypotheses tests, we conducted two post hoc analyses to better determine both psychometric properties and inference for directionality of the tested model. Specifically, despite the theoretical and empirically validated distinction between positive emotions and PsyCap, given the high correlation between PsyCap and positive emotions in this study, we conducted a confirmatory factor analysis to better distinguish these two constructs in terms of measurement. Each item was fit to its latent variable using maximum likelihood techniques in structural equation modeling (using Mplus 3.1). Fit indices for the CFA were generally acceptable (CFI $=.93$, RMSEA $=.06$, standardized root mean square residual [SRMR] =.05), suggesting that despite a strong correlation, measurement of the constructs was generally discriminatory and provides further construct validity support.

A second post hoc analysis was also conducted to test competing theoretical models. First, although we leveraged Lazarus's cognitive mediation theory to describe the relationship between PsyCap and positive emotions, other researchers have suggested that perhaps emotions precede cognitions (e.g., Goleman, Boyatzis, \& McKee, 2002). Given that the research design applied in this study was not experimental and thus cannot account for ordering effects of phenomena, we utilized path analysis in structural equation modeling to compare the two models. 


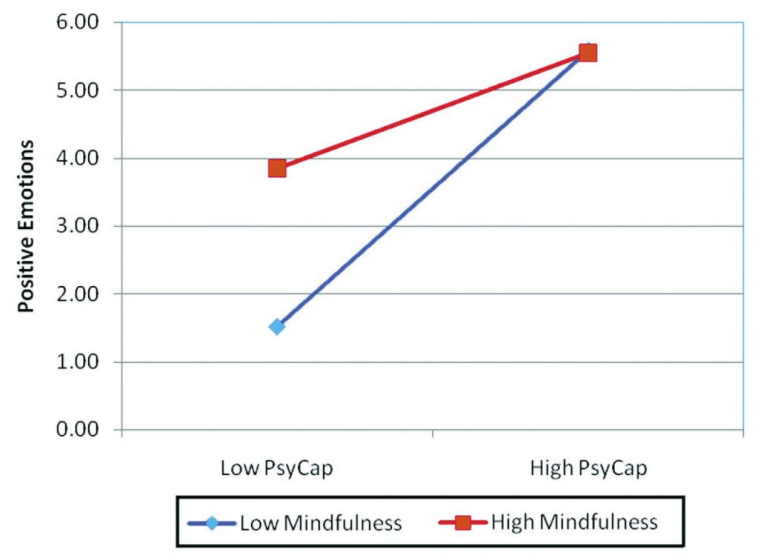

Figure 2: Interaction of Psychological Capital (PsyCap) and Mindfulness on Positive Emotions (Interaction is significant at $p<.05$.)

First, we modeled the data as the theoretical model as shown in Figure 1. This model yielded significant paths consistent with the regression models and generally acceptable model fit indices (CFI $=.95$, RMSEA $=.08$, SRMR $=.08$ ). Next, we fit the data to a model beginning with positive emotions leading to PsyCap (with the mindfulness interaction) and PsyCap leading to the attitudes and behaviors. This model produced a slightly less optimal fit than the hypothesized model $(\mathrm{CFI}=.90$, RMSEA $=.15$, SRMR $=.10)$. The two models were compared using a chi-square difference significance test, which indicated that the hypothesized model with PsyCap leading to positive emotions was a significantly better fit to the data than a model beginning with positive emotions and leading to PsyCap $\left(\Delta \chi^{2}=17.5, p<.01\right)$. Although this model comparison does not demonstrate that PsyCap "caused" positive emotions, it does demonstrate that the optimal fit of the data in this case was a model with PsyCap leading to positive emotions and positive emotions leading to the attitudinal and behavioral variables.

\section{Discussion}

Employee resistance is commonly recognized as one of the biggest obstacles and threats to organizations attempting to change to keep up or ahead of evolving internal and external conditions. The results of this study suggest employees' positive psychological capital and positive emotions may be important in countering potential dysfunctional attitudes and behaviors relevant for organizational change. Specifically, the positive resources of employees (i.e., PsyCap and emotions) may combat the negative reactions (i.e., cynicism and deviance) often associated with organizational change. Taking a positive approach, this study also found that employees' positive resources are associated with desired attitudes (emotional engagement) and behaviors (organizational 
citizenship) that previous research has shown to directly and indirectly facilitate and enhance positive organizational change. In other words, in answering the question posed in the title of the article, positive employees' psychological capital and emotions may indeed be an important contribution to positive organizational change.

In addition, employees' awareness of their thoughts and feelings, namely, mindfulness, was found to interact with PsyCap to predict positive emotions. In the observed interaction, when PsyCap is low, high mindfulness seems to compensate for this and individuals may still experience more positive emotions. It is important to note that this effect is stronger at low levels of PsyCap, suggesting that mindful employees have greater opportunity to become aware of thinking patterns that challenge their ability to be hopeful, efficacious, optimistic, and resilient at work, especially during times of organizational change. Such awareness may lead employees to intentionally choose more hopeful, efficacious, optimistic, and resilient ways of dealing with stress and resistance to change.

Besides the impact that employee positivity through PsyCap and emotions has on attitudes and behaviors relevant to positive organizational change and the moderating role of mindfulness, another major finding from the study is the mediating role positive emotions seems to play in the relationship between PsyCap and the attitudes and behaviors. Given that research to date has mainly considered the direct effects of PsyCap on employee work outcomes (e.g., Luthans, Avolio, et al., 2007; Luthans et al., 2005), mediating mechanisms are just starting to be explored to better understand how PsyCap may affect outcomes in the workplace. Results from this study suggest that positive emotions may mediate the relationship between PsyCap and at least the attitudes of cynicism and engagement and the behaviors of citizenship and deviance. In other words, employees who are higher in PsyCap are likely to have more positive emotions and subsequently be more engaged and less cynical and also exhibit more organizational citizenship and less deviant behaviors. In addition, the results also seem to indicate that PsyCap has a stronger direct and independent effect on employee cynicism than the indirect effect of PsyCap through positive emotions. Future research could replicate and extend these findings by examining this meditational model over time during specific organizational discontinuous events and incremental change processes (Tushman \& O'Reilly, 1996).

Finally, the study's findings build more evidence supporting a cognitive mediation theory (see Lazarus, 1993, for overview; Weiss \& Cropanzano, 1996) of employee emotions in the workplace. That is, employees' psychological beliefs, expectancies, and appraisals (i.e., hope, efficacy, optimism, resilience, or PsyCap) may be a good potential source of positive emotions and subsequent employee attitudes and behaviors related to positive organizational change.

\section{Study Limitations}

As with any empirical study, there are methodological limitations that need to be recognized. First, no causal conclusions can be drawn. Specifically, neither experimental manipulation nor random assignment was part of the study design. Thus, causal effects between PsyCap and positive emotions and be- 
tween positive emotions and the identified attitudes and behaviors cannot be determined. For example, one alternative explanation from this study's findings could be that employees highly engaged in their work leads them to have more positive emotions.

In addition to the direction of causality limitation is that the same source was used to gather data on both independent and dependent variables. Podsakoff and colleagues (2003) note that this common source bias can lead to inflated relationships. Thus, this study followed their recommendations to separate data collection of variables over time. This procedure can help minimize but obviously does not eliminate this limitation. However, recently some organizational research methodologists have argued that the threat of common method variance may not be as big a problem as once assumed (see Spector, 2006).

\section{Future Research and Practical Implications}

Future research needs to continue to explore the nomological network of psychological capital, mindfulness, emotions, and other related positive constructs in the context of organizational change. The integration of positive psychology into the field of organizational behavior has provided ample opportunities for researchers to learn how to leverage individual-level positive constructs for improved organization- level outcomes (e.g., see Cameron, 2003; Youssef \& Luthans, 2005). Furthermore, future research should consider the role of additional mediators and moderators as well as the role of differing organizational-level and cultural contextual factors that influence employee psychological capital and positive emotions and how they manifest and impact performance and macro-level organizational change.

Future research should also focus on experimental studies to establish the causal, directional impact of psychological capital and positive emotions. Tugade and Fredrickson (2004) emphasize that positive emotions enhance resilience, and so it is likely that emotions, once manifested, may in turn influence one's subsequent thinking/ cognition (Albarracin \& Kumkale, 2003; Frijda, Manstead, \& Bem, 2006). However, we agree with Lazarus's (1991, 1993) and Fredrickson's (2001) conclusions that cognition (i.e., perceptions, interpretations, appraisals, beliefs) is a starting point and initiator for emotions. Research on initial event categorization and stereotyping helps explain why people are often not aware of the automatic cognitive appraisals that precede their emotions (e.g., see Bargh, 1994, for a review).

Finally, examining the long-term interactive effects and developmental opportunities for psychological capital, positive emotions, and mindfulness provides practical implications for developing more positive workplaces. For example, there is beginning evidence that PsyCap can be developed in short training interventions (e.g., see Luthans et al., 2006; Luthans et al., in press). The results of the current study would indicate that such training may be effective to facilitate positive organizational changes. In addition, based on the nature of the interaction of PsyCap and mindfulness, it seems that developing mindfulness at work, namely, heightened awareness of current thoughts and feelings, can also facilitate positive emotions. Thus, mindfulness may contribute to understanding the process by which the core construct of PsyCap affects employee attitudes and behaviors relevant to positive organizational change and 
how PsyCap can be developed. Although this study only tested the relationships between two measurable positive constructs on relevant attitudes and behaviors, the findings provide beginning support that positive employees may indeed be a very important ingredient in positive organizational change.

\section{References}

Abrahamson, E. (2000). Change without pain. Harvard Business Review, 78(4), 75-79.

Aiken, L. S., \& West, S. G. (1991). Multiple regression: Testing and interpreting interactions. Newbury Park, CA: Sage.

Albarracin, D., \& Kumkale, G. T. (2003). Affect as information in persuasion: A model of affect identification and discounting. Journal of Personality and Social Psychology, 84, 453-469.

Andersson, L. M., \& Bateman, T. S. (1997). Cynicism in the workplace: Some causes and effects. Journal of Organizational Behavior, 18, 449-460.

Armenakis, A. A., \& Bedeian, A. G. (1999). Organizational change: A review of theory and research in the 1990s. Journal of Management, 25, 293-315.

Ashford, S. J. (1988). Individual strategies for coping with stress during organizational transitions. The Journal of Applied Behavioral Science, 24, 19-36.

Avey, J. B., Patera, J. L., \& West, B. J. (2006). Positive psychological capital: A new approach for understanding absenteeism. Journal of Leadership and Organizational Studies, 13, 42-60.

Baer, R. A. (2003). Mindfulness training as a clinical intervention: A conceptual and empirical review. Clinical Psychology: Science \& Practice, 10, 125-143.

Bakker, A. B., van Emmerik, H., \& Euwema, M. C. (2006). Crossover of burnout and engagement in work teams. Work and Occupations, 33, 464-489.

Bandura, A. (1991). Social cognitive theory and self-regulation. Organizational Behavior and Human Decision Processes, 50, 248-287.

Bandura, A. (1997). Self-efficacy: The exercise of control. New York: Freeman.

Bargh, J. A. (1994). The four horsemen of automaticity. In R. S. Wyer \& T. K. Srull (Eds.), Handbook of social cognition (pp. 1-40). Hillsdale, NJ: Lawrence Erlbaum.

Baron, R. M., \& Kenny, D. A. (1986). The moderator-mediator variable distinction in social psychological research: Conceptual, strategic, and statistical considerations. Journal of Personality and Social Psychology, 51, 1173-1182.

Baumeister, R. F., Gailliot, M. T., DeWall, C. N., \& Oaten, M. (2006). Self-regulation and personality: How interventions increase regulatory success, and how depletion moderates the effects of traits on behavior. Journal of Personality, 74, 1773-1801.

Brief, A. P., \& Weiss, H. M. (2002). Organizational behavior: Affect in the workplace. Annual Review of Psychology, 53, 279-307.

Brown, K. W., \& Ryan, R. M. (2003). The benefits of being present: Mindfulness and its role in psychological well-being. Journal of Personality and Social Psychology, 84, 822-848.

Cameron, K. S. (2003). Organizational virtuousness and performance. In K. S. Cameron, J. E. Dutton, \& R. E. Quinn (Eds.), Positive organizational scholarship (pp. 48-65). San Francisco: Berrett-Koehler.

Cameron, K. S., \& Caza, A. (2004). Contributions to the discipline of positive organizational scholarship. American Behavioral Scientist, 47, 731-739.

Cameron, K. S., Dutton, J. E., \& Quinn, R. E. (Eds.). (2003). Positive organizational scholarship. San Francisco: Berrett-Koehler.

Carlson, L. E., Speca, M., Patel, K. D., \& Goodey, E. (2004). Mindfulness-based stress reduction in relation to quality of life, mood, symptoms of stress and levels of cortisol, dehydroepiandrosterone sulfate (DHEAS) and melatonin in breast and prostate cancer outpatients. Psychoneuroendocrinology, 29, 448-471.

Carver, C. S., \& Scheier, M. S. (2002). Optimism. In C. R. Snyder \& S. J. Lopez (Eds.), Handbook of positive psychology (pp. 231-243). Oxford, UK: Oxford University Press.

Cascio, W. F. (2002). Strategies for responsible restructuring. Academy of Management Executive, $16(3), 80-91$.

Chuang, S. C. (2007). Sadder but wiser or happier and smarter? A demonstration of judgment and decision-making. Journal of Psychology, 141, 63-76. 
Dean, J. W., Brandes, P., \& Dharwadkar, R. (1998). Organizational cynicism. Academy of Management Review, 23, 341-352.

Fox, S., \& Spector, P. E. (1999). A model of work frustration-aggression. Journal of Organizational Behavior, 20, 915-931.

Fredrickson, B. L. (1998). What good are positive emotions? Review of General Psychology, 2, 300-319.

Fredrickson, B. L. (2001). The role of positive emotions in positive psychology: The broaden-andbuild theory of positive emotions. American Psychologist, 56, 218-226.

Fredrickson, B. L. (2003a). Positive emotions and upward spirals in organizations. In K. S. Cameron, J. E. Dutton, \& R. E. Quinn (Eds.), Positive organizational scholarship (pp. 241-261). San Francisco: Berrett-Koehler.

Fredrickson, B. L. (2003b). The value of positive emotions. American Scientist, 91, 330-335.

Fredrickson, B. L., \& Levenson, R. W. (1998). Positive emotions speed recovery from the cardiovascular sequelae of negative emotions. Cognition and Emotion, 12, 191-220.

Fredrickson, B. L., \& Losada, M. F. (2005). Positive affect and the complex dynamics of human flourishing. American Psychologist, 60, 678-686.

Fredrickson, B. L., Mancuso, R. A., Branigan, C., \& Tugade, M. M. (2000). The undoing effect of positive emotions. Motivation and Emotion, 24, 237-258.

Fredrickson, B. L., Tugade, M. M., Waugh, C. E., \& Larkin, G. R. (2003). What good are positive emotions in a crisis? A prospective study of resilience and emotions following the terrorist attacks on the United States on September 11th (2001). Journal of Personality and Social Psychology, 84, 365-376.

Frijda, N. H. (1986). The emotions. Cambridge, UK: Cambridge University Press.

Frijda, N. H., Manstead, A. S. R., \& Bem, S. (2006). Emotions and beliefs. Cambridge, UK: Cambridge University Press.

Germer, C. K., Siegel, R. D., \& Fulton, P. R. (2005). Mindfulness and psychotherapy. New York: Guilford.

Gittell, J. H., Cameron, K., Lim, S., \& Rivas, V. (2006). Relationships, layoffs, and organizational resilience: Airline industry responses to September 11. The Journal of Applied Behavioral Science, 42, 300-329.

Goleman, D., Boyatzis, R., \& McKee, A. (2002). Primal leadership: Realizing the power of emotional intelligence. Boston: Harvard Business School Press.

Izard, C. E. (1993). Four systems for emotion activation: Cognitive and noncognitive processes. Psychological Review, 100, 68-90.

Kabat-Zinn, J. (2003). Mindfulness-based interventions in context: Past, present, and future. Clinical Psychology: Science \& Practice, 10, 144-156.

Keyes, C. L. M. (2002). The mental health continuum: From languishing to flourishing in life. Journal of Health and Social Behavior, 43, 207-222.

Langer, E. J. (1997). The power of mindful learning. Reading, MA: Addison-Wesley.

Lazarus, R. S. (1991). Emotion and adaptation. New York: Oxford University Press.

Lazarus, R. S. (1993). From psychological stress to the emotions: A history of changing outlooks. Annual Review of Psychology, 44, 1-21.

Lazarus, R. S. (2006). Emotions and interpersonal relationships: Toward a person-centered conceptualization of emotions and coping. Journal of Personality, 74, 9-46.

Lazarus, R. S., \& Folkman, S. (1984). Stress, appraisal, and coping. New York: Springer.

Lee, K., \& Allen, N. J. (2002). Organizational citizenship behavior and workplace deviance: The role of affect and cognitions. Journal of Applied Psychology, 87, 131-142.

Lord, R. G., Klimoski, R. J., \& Kanfer, R. (2002). Emotions in the workplace: Understanding the structure and role of emotions in organizational behavior. San Francisco: Jossey-Bass.

Luthans, F. (2002a). The need for and meaning of positive organizational behavior. Journal of Organizational Behavior, 23, 695-706.

Luthans, F. (2002b). Positive organizational behavior: Developing and managing psychological strengths. Academy of Management Executive, 16, 57-72.

Luthans, F., Avey, J. B., Avolio, B. J., Norman, S. M., \& Combs, G. M. (2006). Psychological capital development: Toward a micro-intervention. Journal of Organizational Behavior, 27, 387-393.

Luthans, F., Avey, J. B., \& Patera, J. L. (in press). Experimental analysis of a Web-based intervention to develop positive psychological capital. Academy of Management Learning and Education. 
Luthans, F., Avolio, B., Avey, J. B., \& Norman, S. M. (2007). Psychological capital: Measurement and relationship with performance and job satisfaction. Personnel Psychology, 60, 541-572.

Luthans, F., Avolio, B., Walumbwa, F., \& Li, W. (2005). The psychological capital of Chinese workers: Exploring the relationship with performance. Management and Organization Review, 1, 247-269.

Luthans, F., \& Youssef, C. M. (2004). Human, social, and now positive psychological capital manage- ment. Organizational Dynamics, 33, 143-160.

Luthans, F., \& Youssef, C. M. (2007). Emerging positive organizational behavior. Journal of Management, 33, 321-349.

Luthans, F., Youssef, C. M., \& Avolio, B. J. (2007). Psychological capital: Developing the human competitive edge. Oxford, UK: Oxford University Press.

Lyubomirsky, S., King, L., \& Diener, E. (2005). The benefits of frequent positive affect: Does happiness lead to success. Psychological Bulletin, 131, 803-855.

Martin, A. J., Jones, E. S., \& Callan, V. J. (2005). The role of psychological climate in facilitating adjustment during organizational change. European Journal of Work and Organizational Psychology, 14, 263-289.

Masten, A. S., \& Reed, M. G. J. (2002). Resilience in development. In C. R. Snyder \& S. Lopez (Eds.), Handbook of positive psychology (pp. 74-88). Oxford, UK: Oxford University Press.

May, D. R., Gilson, R. L., \& Harter, L. M. (2004). The psychological conditions of meaningfulness, safety and availability and the engagement of the human spirit at work. Journal of Occupational \& Organizational Psychology, 77, 11-37.

Mishra, K. E., Spreitzer, G. M., \& Mishra, A. K. (1998). Preserving employee morale during downsizing. MIT Sloan Management Review, 39(2), 83-95.

Nelson, D., \& Cooper, C. (Eds.). (2007). Positive organizational behavior: Accentuating the positive at work. Thousand Oaks, CA: Sage.

Ortony, A., Clore, G. L., \& Collins, A. (1988). The cognitive structure of emotions. Cambridge, UK: Cambridge University Press.

O'Toole, J. (1995). Leading change: Overcoming the ideology of comfort and the tyranny of custom. San Francisco: Jossey-Bass.

Payne, R. L., \& Cooper, C. L. (2001). Emotions at work: Theory, research and applications in management. New York: John Wiley.

Podsakoff, P. M., MacKenzie, S. C., Lee, J., \& Podsakoff, N. P. (2003). Common method biases in behavioral research: A critical review of the literature and recommended remedies. Journal of Applied Psychology, 88, 879-903.

Porras, J. I., \& Silvers, R. C. (1994). Organizational development and transformation. In W. L. French, C. H. Bell, \& R. A. Zawacki (Eds.), Organizational development and transformation: Managing effective change (pp. 82-110). New York: Irwin McGraw-Hill.

Pugh, S. D., Skarlicki, D. P., \& Passell, B. S. (2003). After the fall: Layoff victims' trust and cynicism in re-employment. Journal of Occupational and Organizational Psychology, 76, 201-212.

Quick, J. C., \& Quick, J. D. (2004). Healthy, happy, productive work. Organizational Dynamics, 33, 329-337.

Reichers, A. E., Wanous, J. P., \& Austin, J. T. (1997). Understanding and managing cynicism about organizational change. Academy of Management Executive, 11(1), 48-59.

Roberts, L. M. (2006). Shifting the lens on organizational life: The added value of positive scholarship. Academy of Management Review, 31, 292-305.

Schachter, S., \& Singer, J. (1962). Cognitive, social, and physiological determinants of emotional state. Psychological Review, 69, 379-399.

Schwarz, N., \& Clore, G. L. (1983). Mood, misattribution, and judgments of well-being: Informative and directive functions of affective states. Journal of Personality and Social Psychology, $45,513-523$.

Seligman, M. E. P. (1998). Learned optimism. New York: Pocket Books.

Seligman, M. E. P., \& Csikszentmihalyi, M. (2000). Positive psychology. American Psychologist, $55,5-14$.

Snyder, C. R. (2002). Hope theory: Rainbows in the mind. Psychological Inquiry, 13, 249-276.

Snyder, C. R., Irving, L. M., \& Anderson, J. R. (1991). Hope and health. In C. R. Snyder (Ed.), Handbook of social and clinical psychology (pp. 285-305). Oxford, UK: Oxford University Press. 
Spector, P. E. (2006). Method variance in organizational research: Truth or urban legend? Organizational Research Methods, 9, 221-232.

Stajkovic, A. S. \& Luthans, F. (1998a). Self-self efficacy and work-related performance: A metaanalysis. Psychological Bulletin, 124, 240-261.

Stajkovic, A. S. \& Luthans, F. (1998b). Social cognitive theory and self-efficacy: Going beyond traditional motivational and behavioral approaches. Organizational Dynamics, 26, 62-74.

Stanley, D. J., Meyer, J. P., \& Topolntsky, L. (2005). Employee cynicism and resistance to organizational change. Journal of Business and Psychology, 19, 429-459.

Staw, B. M., \& Barsade, S. G. (1993). Affect and managerial performance: A test of the sadder-butwiser vs. happier-and-smarter hypotheses. Administrative Science Quarterly, 38, 304-331.

Staw, B. M., Sutton, R. I., \& Pelled, L. H. (1994). Employee positive emotion and favorable outcomes at the workplace. Organization Science, 5, 51-71.

Sternberg, R. J. (2000). Images of mindfulness. Journal of Social Issues, 56, 11-26.

Strebel, P. (1996). Why do employees resist change? Harvard Business Review, 74(3), 86-92.

Teasdale, J. D., Segal, Z., \& Williams, J. M. G. (1995). How does cognitive therapy prevent depressive relapse and why should attentional control (mindfulness) training help? Behavior Research and Therapy, 33, 25-39.

Tugade, M. M., \& Fredrickson, B. L. (2004). Resilient individuals use positive emotions to bounce back from negative emotional experiences. Journal of Personality and Social Psychology, 86, 320-333.

Tugade, M. M., Fredrickson, B. L., \& Barrett, L. (2004). Psychological resilience and positive emotional granularity. Journal of Personality, 72, 1161-1190.

Tushman, M. L., \& O'Reilly, C. A. (1996). Ambidextrous organizations: Managing evolutionary and revolutionary change. California Management Review, 38(4), 8-30.

Wallace, B. A., \& Shapiro, S. L. (2006). Mental balance and well-being. American Psychologist, 61, 690-701.

Wanous, J. P., Reichers, A. E., \& Austin, J. T. (2000). Cynicism about organizational change: Measurement, antecedents, and correlates. Group and Organization Management, 25, 132-153.

Watson, D., Clark, L. A., \& Tellegen, A. (1988). Development and validation of brief measures of positive and negative affect: The PANAS scales. Journal of Personality and Social Psychology, 54, 1063-1070.

Weick, K. E., \& Quinn, R. E. (1999). Organizational change and development. Annual Review of Psychology, 50, 361-386.

Weick, K. E., \& Sutcliffe, K. M. (2001). Managing the unexpected: Assuring high performance in an age of complexity. San Francisco: Jossey-Bass.

Weick, K. E., \& Sutcliffe, K. M. (2006). Mindfulness and the quality of organizational attention. Organization Science, 17, 514-524.

Weick, K. E., Sutcliffe, K. M., \& Obstfeld, D. (1999). Organizing for high reliability: Processes of collective mindfulness. In B. M. Staw \& R. Sutton (Eds.), Research in organizational behavior (pp. 81-123). Greenwich, CT: JAI.

Weiss, H. M., \& Cropanzano, R. (1996). Affective events theory. In B. Staw \& L. L. Cummings (Eds.), Research in organizational behavior (pp. 1-74). Greenwich, CT: JAI.

Wright, T. A. (2003). Positive organizational behavior: An idea whose time has truly come. Journal of Organizational Behavior, 24, 437-442.

Wright, T. A., \& Cropanzano, R. (2004). The role of psychological well-being in job performance. Organizational Dynamics, 33, 338-351.

Wright, T. A., \& Staw, B. M. (1999). Affect and favorable work outcomes: Two longitudinal tests of the happy-productive worker thesis. Journal of Organizational Behavior, 20, 1-23.

Youssef, C. M., \& Luthans, F. (2005). Resiliency development of organizations, leaders and employees: Multi-level theory building for sustained performance. In W. Gardner, B. J. Avolio, \& F. O. Walumbwa (Eds.), Authentic leadership theory and practice. Origins, effects, and development (pp. 303-343). Oxford, UK: Elsevier. 
James B. Avey is an assistant professor of management in the Department of Management, Central Washington University.

Tara S. Wernsing is a doctoral candidate in the Department of Management, Gallup Leadership Institute, University of Nebraska-Lincoln.

Fred Luthans is the George Holmes Distinguished Professor of Management, Department of Management, Gallup Leadership Institute, University of Nebraska-Lincoln. 